\title{
Thoracic radiography and oxidative stress indices in heartworm affected dogs
}

\author{
P. K. Rath ${ }^{1}$, S. K. Panda ${ }^{1}$, B. P. Mishra², R. C. Patra ${ }^{3}$ and I. Nath ${ }^{4}$
}

1. Department of Veterinary Pathology, College of Veterinary Science \& Animal Husbandry, OUAT, Bhubaneswar, Odisha, India; 2. Veterinary Dispensary, Rajsunakhala, Nayagarh, Odisha, India; 3. Department of Clinical Veterinary Medicine, College of Veterinary Science \& Animal Husbandry, OUAT, Bhubaneswar, Odisha, India; 4. Department of Veterinary Surgery \& Radiology, College of Veterinary Science \& Animal Husbandry, OUAT, Bhubaneswar, Odisha, India. Corresponding author: P. K. Rath, e-mail: drpkrath78@gmail.com, SKP: drsusen_panda@yahoo.com, BPM: bidyutmishraivri@gmail.com, RCP: rcpatra@gmail.com, IN: indravet@yahoo.co.in Received: 30-05-2014, Revised: 25-07-2014, Accepted: 31-07-2014, Published online: 15-09-2014

doi: 10.14202/vetworld.2014.689-692. How to cite this article: Rath PK, Panda SK, Mishra BP, Patra RC, Nath I (2014) Thoracic radiography and oxidative stress indices in heartworm affected dogs, Veterinary World 7(9): 689-692.

\begin{abstract}
Aim: The aim was to study the pathomorphological changes through thoracic radiography and status of oxidative stress parameters in heartworm affected dogs in Odisha.

Materials and Methods: A total of 16 dogs with clinically established diagnosis of dirofilariasis by wet blood smear and modified Knott's test and equal numbers of dogs as control were included in this study. The present study was conducted in heartworm affected dogs to see the pathomorphological changes through thoracic radiography. Similarly, the evaluation was undertaken for observing any alterations in oxidative stress status in affected as well as non-affected, but healthy control dogs by adopting standard procedure.
\end{abstract}

Results: Thoracic radiography revealed cardiac enlargement, round heart appearance suggestive of right ventricular hypertrophy, tortuous pulmonary artery and darkening of lungs. Alterations in oxidative stress indices showed a significant rise of lipid peroxidase activity, non-significant rise of superoxide dismutase and a significant although reverse trend for catalase levels in affected dogs in comparison to Dirofilaria negative control but apparently healthy dogs.

Conclusions: Radiographic changes, as well as alterations in oxidative stress parameters, may not be diagnostic for heartworm infection, but useful for detecting heartworm disease, assessing severity and evaluating cardiopulmonary parenchyma changes and gives a fair idea about the degree of severity of the disease. It aids as contributing factors in disease pathogenesis.

Keywords: Dirofilaria immitis, heartworm, oxidative stress, radiography.

\section{I ntroduction}

Dirofilariasis popularly known as "heartworm disease" is a common and important disease affecting dogs, cats, foxes and wolves in tropics, sub-tropics and temperate regions of the world [1] The species, Dirofilaria immitis is the causal agent of heartworm disease in dogs [2]. Dog is considered to be a definitive host, the mosquito Culex being the intermediate host. The disease has a worldwide distribution. Canine dirofilariasis now recognized not only as a veterinary problem, but also a zoonoses in many parts of the world $[3,4]$. In recent years, there is a conspicuous upsurge in the prevalence of heartworm disease in canine in India. Several factors such as global warming, uncertainty in the seasonal cycle with changes in ever increasing vector's population, rapid and continuous animal movement between different countries play an important role in the high prevalence of this disease [5]. Detection of Dirofilaria through wet blood smear and modified Knott's test is the easiest, inexpensive and reliable diagnostic method, but

Copyright: The authors. This article is an open access article licensed under the terms of the Creative Commons Attributin License (http:// creative commons.org/licenses/by/2.0) which permits unrestricted use, distribution and reproduction in any medium, provided the work is properly cited. needs professional expertise to differentiate between D. immitis and Acanthocheilonema reconditum. The pathophysiological response to heartworm infection is mainly due to the presence of adult worms in the vital organs of the body, that is., in right ventricles of the heart and pulmonary artery [6]. Similarly, the worm burden, host immune response and duration of infection determine the severity of infection by altering the path morphology of several organs, which can be recognized through radiography [7].

Thoracic radiography singularly may not be diagnostic for heartworm infection but useful for detecting heartworm disease, assessing severity and evaluating cardiopulmonary parenchymal changes $[8,9]$. Post mortem examination and detection of adult worms in the heart, followed by histopathology are very important diagnostic tools in animals that succumb to chronic heart worm infestation. Oxidative stress plays a vital role in the pathogenesis of different diseases and gives a fair idea about the degree of severity of the disease [10-12]. Superoxide dismutase (SOD), lipid peroxidase (LPO) and catalase are the major antioxidant enzymes present in red blood cell (RBC) to counteract the toxic effects of reactive oxygen species such as superoxide radicals and hydrogen peroxides [13], which are also considered as 
indicators of oxidative stress in Dirofilaria affected dogs.

In this study, an attempt was made to see the pathomorphological changes through X-ray and image intensifier TV system (C-arm examination) and to study the alterations in oxidative stress indices in heartworm affected dogs in Odisha.

\section{Materials and Methods}

\section{Ethical approval}

The experiment was carried out according to the national regulations on animal welfare and Institutional Animal Ethical Committee.

\section{Animals}

Pet and stray dogs of both sexes with varying ages and breeds were included in this study from several sources viz. Teaching Veterinary Clinical Complex of the College mostly dealing with pet dogs of private owners, Police Dog Squad and Animal Birth Control Program of Bhubaneswar Municipal Corporation at Veterinary Polyclinic, Sahid Nagar dealing with sterilization of stray dogs.

\section{Experiment design}

Dogs were screened for dirofilariasis on the basis of clinical signs and blood examinations (wet blood smear and modified Knott's test). In this study, motile microfilariae of more than 10 /microscopic field in wet blood smear and more than 5 in modified Knott's test was considered as heavily positive for Dirofilaria infestation. Of these, 16 animals were subjected for thoracic radiography and oxidative stress evaluation which were compared against equal numbers of Dirofilaria negative but apparently healthy dogs.

\section{Procedures}

Radiography was conducted by C-arm examinations and X-ray. A volume of milliliter blood in heparinized test tube was collected from the cephalic vein without giving much stress to dogs for oxidative stress indices study. Three parameters such as LPO, SOD and catalase activity were taken to measure the stress indices. Membrane peroxidation damage in the erythrocyte was expressed in units of malondealdehyde production by modified method of Stock and Dormandy [14] as described by Placer et al. [15]. The SOD activity was estimated by methods of Marklund and Marklund [16] with certain suggested modification by Menami and Yoshikawa [17] using diluted nitroblue tetrazolium as substrate. Estimation of catalase activity in 10\% RBC hemolysate was done as per the procedure described by Cohen et al. [18].

\section{Results and Discussion}

\section{Thoracic radiography}

Radiographic evaluation through C-arm examination (Figure-1) of affected animals with a heavy load of microfilariae in the blood during screening revealed cardiomegaly, round heart appearance suggestive of right ventricular hypertrophy, tortuosity of the pulmonary artery and darkening of lungs. Radiographic changes associated with heartworm disease include right ventricular enlargement (Figure-2), increased prominence of the main pulmonary artery segments, increased size and density of the pulmonary arteries, arterial tortuosity. Similar findings were observed by Polizopoulou et al. [9], which may be due to the presence of adult worms in right ventricles and pulmonary artery [6] thereby causing certain pathomorphological changes in these organs. Persistence of the parenchyma changes related with severity and chronicity of the disease [6].

\section{Oxidative stress indices}

Oxidative stress indices like LPO, SOD and catalase, were done to assess the tissue damage caused by dirofilariasis in canine. For this purpose, 16 samples each from affected and non-affected animals as control were utilized. The LPO value (nm of

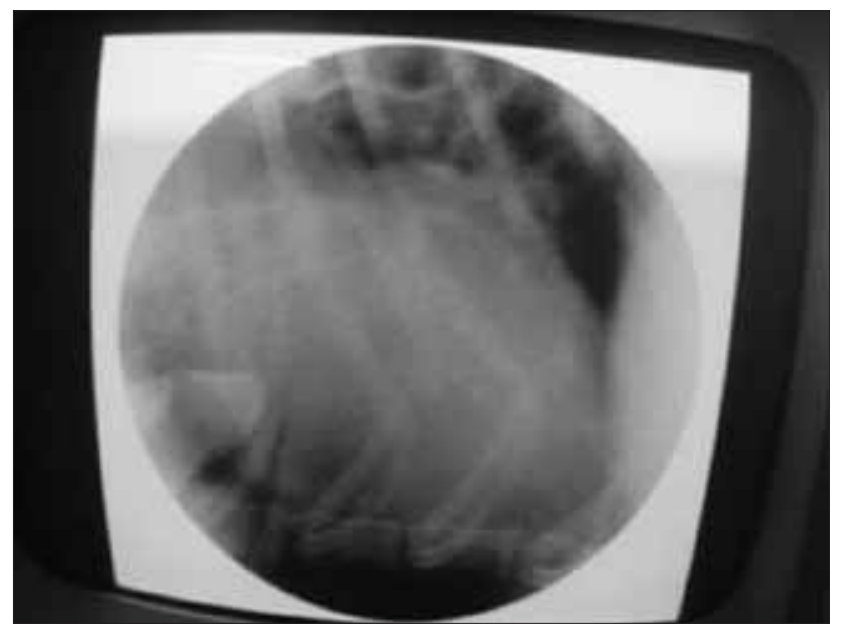

Figure-1: C-arm examination showing cardiomegaly.

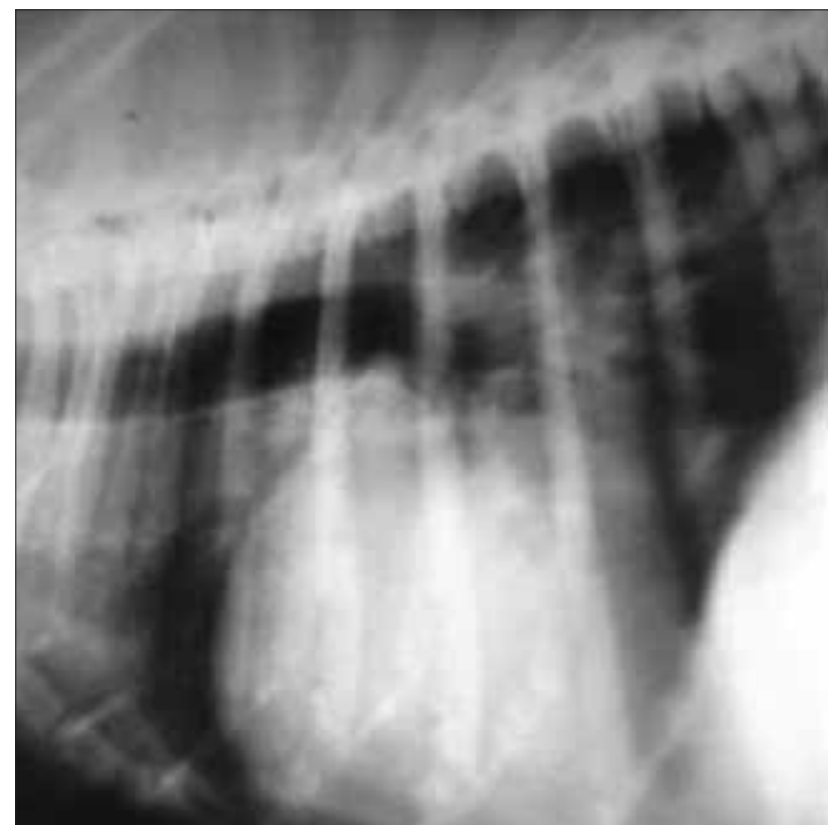

Figure-2: X-ray showing cardiomegaly. 
malondialdehyde/ml) in average was $33.41( \pm 1.01)$ with a range of minimum 27.54 and maximum 39.21 in the filaria positive dogs which was significantly $(\mathrm{p}<0.05)$ higher than the control with an average level of activity at $19.46( \pm 1.22)$ ranging from a minimum of 15.07 to 25.47 (Figure-3). The SOD activity (unit/ mg of $\mathrm{Hb})$ varied from 0.99 to 2.72 with mean $( \pm \mathrm{SE})$ at $2.15( \pm 0.12)$. Although this activity was higher than the control counterpart showing an average of 1.51 $( \pm 0.22)$ of activity, the difference was non-significant (Figure-4). The catalase level (unit/mg of $\mathrm{Hb}$ ) in the affected dogs, on the other hand, hovered between 0.05 and 0.21 mean $( \pm$ SE) being $0.12( \pm 0.01)$. The control non-affected animals showed the activity

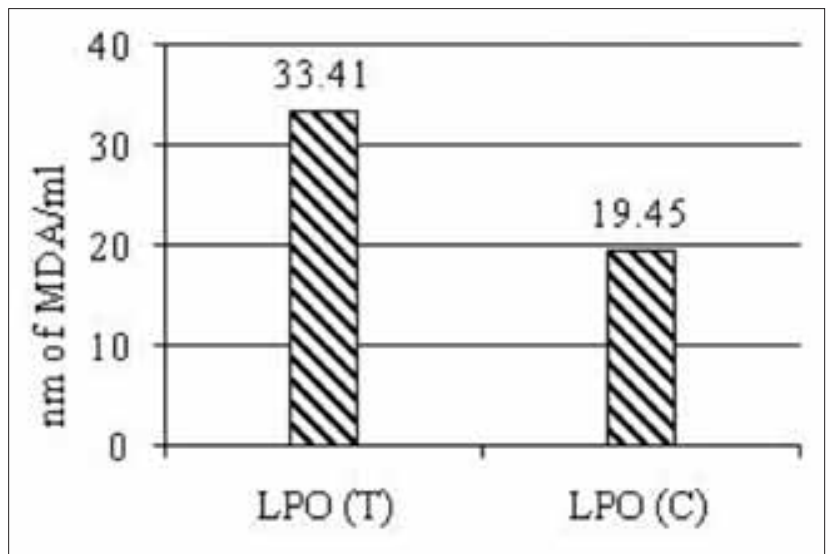

Figure-3: Lipid peroxidase activity level.

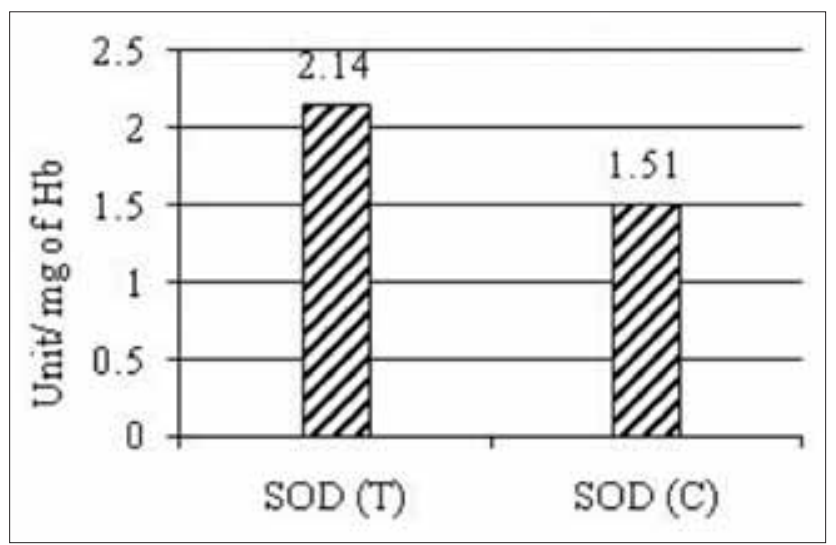

Figure-4: Superoxide dismutase activity level.

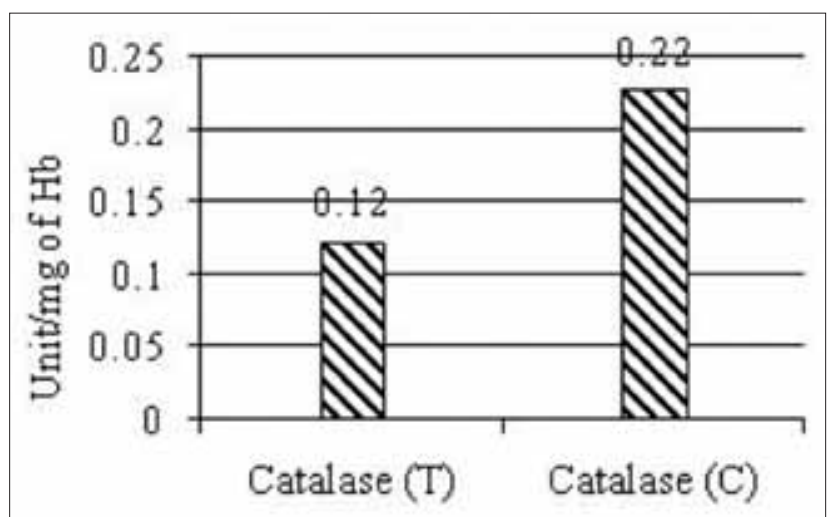

Figure-5: Catalase activity level. within 0.09 and 0.41 with an average of $0.23( \pm 0.03)$. The difference was significant at $\mathrm{p}<0.05$ (Figure-5). Radiographic changes relating to pathomorphological alterations in heart, lungs and pulmonary artery in this study were in conformity with McCall et al. [19]. Dimri et al. [20] concluded about a significant rise of LPO activity and non-significant rise of SOD and a significant although reverse trend for catalase levels in affected dogs in comparison to Dirofilaria negative, but apparently healthy dogs, which corroborate with the present findings.

\section{Conclusions}

Radiographic examination through c-arm and $\mathrm{x}$-ray of the thoracic region showed obvious cardiopulmonary parenchyma changes owing to the presence of adult worms in these vital organs. Heavy load of adult heartworms and peripheral microfilaria result in certain alterations in oxidative stress parameters directing the disease pathogenesis process to a critical level, which may aid in assessing disease severity in chronic cases.

\section{Authors' Contributions}

RCP and IN were involved in the design of the experiment. PKR carried out the research experiment and data collection under the supervision of SKP. PKR and BPM collected materials for the manuscript and prepared the first draft before being revised by all authors. All authors read and approved the final manuscript.

\section{Acknowledgments}

The authors acknowledge the Dean, College of Veterinary Science and Animal Husbandry, OUAT, Bhubaneswar, Odisha for providing the necessary facilities and funds to carry out the present research work.

\section{Competing I nterests}

The authors declare that they have no competing interests.

\section{References}

1. Souls By, E.J.L. (1982) Helminths, Arthropods and Protozoa of Domesticated Animals. Bailliere Tindal, London.

2. Genchi, C., Kramer, L.H. and Prieto, G. (2001) Epidemiology of canine and feline dirofilariasis: A global view. In: Simon, F., Genchi, C. editors. Heartworm Infection in Humans and Animals. Ediciones. Universidad de Salamanca, Spain. p121-133.

3. Pampiglione, S., Rivasi, F., Angeli, G., Boldorini, R., Incensati, R., Pastormerlo, M., Pavesi, M. and Ramponi, A. (2001) Dirofilariosis due to Dirofilaria repens in Italy, an emerging zoonosis: Report of new cases. Histopathology., 38: 344-354.

4. Miyoshi, T., Tsubouchi, H., Iwasaki, A., Shiraishi, T., Nabeshima, K. and Shirakusa, T. (2006) Human pulmonary dirofilariasis: A case report and review of the recent Japanese literature. Respirology., 11(3):343-347.

5. Morchón, R., Carretón, E., González-Miguel, J. and Mellado-Hernández, I. (2012) Heartworm disease (Dirofilaria immitis) and their vectors in Europe - new 
distribution trends. Front. Physiol., 3: 196.

6. Hoch, H. and Strickland, K. (2008) Canine and feline dirofilariasis: Life cycle, pathophysiology, and diagnosis. Compend Contin Educ Vet., 30: 133-140.

7. Kramer, L.H. (2009) Pathogenesis of Dirofilaria spp. Infections. In: Morchón R., Simón, F., Montoya, J.A., Genchi, C. editors. Proceedings of Second European Dirofilaria Days, 16-18 September. Salamanca, Spain. p.116-123.

8. Rawlings, C.A., Losonsky, J.M., Lewis, R.E. and McCall, J.W. (1981) Development and resolution of radiographic lesions in canine heartworm disease. J. Am. Vet. Med. Assoc., 178(11): 1172-1177.

9. Polizopoulou, Z.S., Koutinas, A.F., Saridomichelakis, M.N., Patsikas, M.N., Leontidis, L.S., Roubies, N.A. and Desiris, A.K. (2000) Clinical and laboratory observations in 91 dogs infected with Dirofilaria immitis in Northern Greece. Vet. Rec., 146(16): 466-469.

10. Camkerten, I., Sahin, T., Borazan, G., Gokcen, A., Erel, O. and Das, A. (2009) Evaluation of blood oxidant/antioxidant balance in dogs with sarcoptic mange. Vet. Parasitol., 161(1-2): 106-109.

11. Singh, S.K., Dimri, U., Sharma, M.C., Swarup, D. and Sharma, B. (2011) Determination of oxidative status and apoptosis in peripheral blood of dogs with sarcoptic mange. Vet. Parasitol., 178(3-4): 330-338.

12. Panda, D., Patra, R.C., Nandi, S. and Swarup, D. (2009) Oxidative stress indices in gastroenteritis in dogs with canine parvoviral infection. Res. Vet. Sci., 86(1): 36-42.

13. Moral, J., Puge, L.K. and Mochelson, A.M. (1977)
Comparative study of superoxide dismutase, catalase and glutathione peroxidase levels in erythrocytes of different animals. Biochem. Biophys. Res. Commun., 77(4): 1525-1535.

14. Stocks, J. and Dormandy, T.L. (1971) The autoxidation of human red cell. Lipid induced by hydrogen peroxide. $B r . J$. Haematol., 20(1): 95-111.

15. Placer, Z.A., Cushman, L. and Johnson, B. (1966) Estimation of product of lipid peroxidation (malonydialdehyde) in biochemical system. Anal. Biochem., 16(2): 1359-1364.

16. Marklund, S. and Marklund, G. (1974) Involvement of superoxide anion radical in the auto oxidation of pyrogalol and a convenient assay for superoxide dismutase. Eur. $J$. Biochem., 47: 469-474.

17. Minami, M. and Yoshikawa, H. (1979) Simplified assay method of superoxide Dismutase activity of clinical use. Clin. Chem. Acta., 92(3): 337-342.

18. Cohen, G., Dembiec, D. and Marcus, J. (1970) Measurement of catalase activity in tissues extract. Anal. Biochem., 34: 30-38.

19. McCall, J.W., Guerrero, J., Genchi, C. and Krammer, I. (2004) Recent advances in Heartworm disease. Vet. Parasitol., 125(1-2):105-130.

20. Dimri, U., Singh, S.K., Sharma, M.C., Behera, S.K., Kumar, D. and Tiwari, P. (2012) Oxidant/antioxidant balance, minerals status and apoptosis in peripheral blood of dogs naturally infected with Dirofilaria immitis. Res. Vet. Sci., 93(1):296-299. 